\title{
Genotype-8: A Modern Family Member of Hepatitis C Virus
}

\author{
Sai Krishna Gudi ${ }^{1, *}$, Manik Chhabra ${ }^{2}$, Muhammed Rashid ${ }^{3}$ \\ ${ }^{1}$ College of Pharmacy, Rady Faculty of Health Sciences, University of Manitoba, CANADA. \\ ${ }^{2}$ Department of Pharmacy Practice, Indo-Soviet Friendship College of Pharmacy, Moga, Punjab, INDIA. \\ ${ }^{3}$ Department of Pharmacy Practice, Sri Adichunchanagiri College of Pharmacy, Adichunchanagiri University, BG Nagara, Karnataka, \\ INDIA.
}

\begin{abstract}
Hepatitis C Virus (HCV) is a highly diverse and pervasive disease around the globe, with a prevalence ranging from 1.5 to $2.3 \%$. With wide genetic variability, it is classified into seven Genotypes (GT) with 67 subtypes. The sighting of a modern HCV GT-8 ratifies its endemic character in India, particularly in the Punjab State. Getting familiarized and making aware of the HCV genotypes and subtypes is necessarily essential in establishing the optimal treatment regimen.
\end{abstract}

Key words: Hepatitis C, RNA virus, Epidemiology, Genotype Classification, Genotype 8, India.

\section{INTRODUCTION}

Hepatitis C Virus (HCV) is a singlestranded RNA virus which belongs to the genus Hepacivirus of family Flaviviridae and was discovered for the very first time in the year 1989. ${ }^{1}$ It acts as a major cause for Chronic Liver Disease (CLD), Cirrhosis and Hepato-Cellular Carcinoma (HCC). ${ }^{2}$ $\mathrm{HCV}$ can be transmitted through various routes, which includes the direct contact with the infected blood and body fluids, invasive medical procedures, i.e., surgery, body tattooing, IV drug abuse and sexual intercourse. ${ }^{3} \mathrm{HCV}$ was categorized into seven genotypes with 67 subtypes until the discovery of genotype $8{ }^{4}$ The identification of novel genotype eight has added 17 subtypes to the family of HCV, which make up the total to 8 genotypes with 84 subtypes. ${ }^{5}$

\section{Epidemiology}

Among the different types of Hepatitis, $\mathrm{HCV}$ is considered as the leading cause of morbidity and mortality across the world. Since the past two decades, the global mortality of HCV has inclined from 0.89 million to 1.45 million and emerged as the seventh leading cause of death worldwide. ${ }^{4}$ When it comes to the deaths related to HCV, the continents like Asia and Africa are predominantly affected than other continents ( $\geq 33.50$ deaths per 100,000 population per year). In particular, there observed $52 \%$ higher deaths in east and south Asia. ${ }^{6}$ Unlike the other communicable diseases which prevalently occur in low-income countries, Hepatitis is highly endemic in middle and high-income countries. As HCV is chronic and life-long infection, it could progress in liver damage, which leads to cirrhosis and hepatocellular carcinoma.

\section{HCV in Indian Context}

The findings from a recent systematic review infer that the prevalence of HCV infected adults globally is $2.5 \%$ and $64.4 \%$ viraemic load in Asia. ${ }^{5}$ Among the HCV genotypes, Genotype 1 is considered as the most common with an estimate of $49.1 \%$, followed by genotype 3, 4 and 2 with a prevalence rate of $17.9 \%, 16.8 \%$ and $11.0 \%$ respectively. The distribution of G1, G2, G3, G4, G5, G6 and mixed genotypes in Asia are iden-
Submission Date: 11-06-2019; Revision Date: 04-09-2019; Accepted Date: 3-10-2019

DOI: 10.5530/ijper.53.4s.146 Correspondence: Dr. Sai Krishna Gudi, Research Graduate, College of Pharmacy, Rady Faculty of Health Sciences, University of Manitoba, CANADA.

Phone: +1 431 336(8099)

E-mail: sknanu06@gmail.com

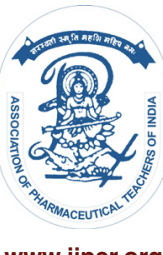

www.ijper.org 
tified as $46.6 \%, 18.6 \%, 22.4 \%, 1.0 \%, 0.1 \%, 7.0 \%$ and $4.3 \%$ respectively. ${ }^{7}$ In India, HCV prevalence has been estimated at $1-1.9 \%$ and as per the study in West Bengal, an increasing drift was found from children aged below 10 years $(0.31 \%)$ to adults aged 60 years $(1.85 \%)$; however, there is no significant difference observed between males and females. ${ }^{5}$ Various efforts such as, active screening of high-risk groups for $\mathrm{HCV}$ infection, provision of safe blood and blood products, avoiding unsafe injection practices, adequate awareness and education and effective vaccination programs have been implemented in order to prevent HCV in India, which eventually reduced the overall prevalence of HCV in India. Besides, the introduction of new direct-acting antiviral agents such as Sofosbuvir (in March 2015) followed by Ledipasvir and Daclatasvir (in December 2015) into the Indian market has strengthened the effective management of chronic HCV. ${ }^{8}$ According to a study conducted by Mahajan et al. has inferred that the HCV infection is mostly observed in the middle-aged rural males and the most observed risk factors were dental treatment, use of reused syringes and needles. ${ }^{7}$

\section{HCV Genome}

HCV is a single-stranded RNA virus, which is 9600 nucleotides in length that encodes for 3000 amino acids. ${ }^{9}$ All the seven genotypes exhibit their variability of about $30 \%$ at their nucleotide level. The single open reading frame forms a composition of the HCV genome, which encodes for ten proteins. These ten proteins consist of three structural proteins and seven non-structural proteins. ${ }^{10}$ Genotypes $1-4$ and 6 have further multiple subtypes of genomes based on their genetic variability, while genotype 5 has only one subtype. ${ }^{11}$ In the year 2006, genotype 7 a was recognized for the very first time in the population of the democratic republic of Congo, further its subtype was identified and was named as GT7b. ${ }^{12}$ Infection with Genotype 1 is the most all over the world, with the prevalence of $46 \%$ in the regions of Australia, Europe and North America. Genotype 3 has second the highest prevalence, i.e., 30\%, after genotype 1 with predominance in the South Asian region, especially in India. It is observed that $23 \%$ of the HCV infections are due to genotypes 2, 4 and 6, while genotypes 7 and five together account for $<1 \%$ of the cases. ${ }^{13}$ Among all RNA viruses, HCV virus is believed to have a higher mutation rate, i.e., $2.5 \times 10^{-5}$ mutations per nucleotide per genome. ${ }^{8}$ Borgia MS et al. have reported the identification of newer genotype, i.e., GT 8 in Canada (in people those who are migrated from Punjab, India). ${ }^{5}$ A study conducted in Uttar Pradesh by Prakash et al. reported that the prevalent genotypes and subtypes of HCV was found to be $25 \%, 2.9 \%, 0.25 \%, 68.07 \%$, $2.2 \%, 0.49 \%, 0.74 \%$ and $0.24 \%$ for the genotypes $1 \mathrm{a}$, GT1b, GT1c, GT3a, GT3b, GT3g, GT3i and GT4a, respectively. ${ }^{14}$ Whereas HCV genotypes GT2, GT5 and GT6 were not detected in that population and GT3a and GT1b were the commonest.

\section{HCV Genotype-8}

The novel HCV genotype eight was discovered by Borgia MS and team in four patients, who were taking part in POLARIS study in Canada, who were the immigrants of Punjab, India. ${ }^{5}$ Genotype 8 is distinct from other genotypes, with a variation of more than $30 \%$ in genotypic sequence and the NS-5B gene regions have an absence of 90 amino acids. Patients infected with GT 8 were previously misdiagnosed with GT 5 infection, which was performed by using a LiPA or Abbott Real Time PCR commercial assay. ${ }^{4}$ Borgia et al. also mentioned that among all four patients sustained viral response was achieved in all the four patient, two patients were on sofosbuvir/velpatavir/voxilaprevir regimen for eight months while other two were on sofosbuvir/ledipasvir for months and sofosbuvir/daltatavir for 12 months respectively. Regions like NS3, NS5A and NS5B were investigated for amino acid positions responsible for resistance and no amino acid responsible for resistance was present NS5 B region. NS5A, RASs, Q30S and Y93S region amino acid shows resistance to ledipasvir. ${ }^{5}$

\section{CONCLUSION}

In order to develop better sophisticated drug regimen for the HCV treatment, a keen knowledge regarding the novel genotypes is required at the population level, not just limiting it to the healthcare policy decision makers. There exists an epidemiological gap, as all the four patients reside in Canada; however, they were originally from India. Thus, further robust research is needed in the resource-limited countries like India where the HCV is considered as an epidemic, to discover additional patients with GT 8.

\section{ACKNOWLEDGEMENT}

None.

\section{CONFLICT OF INTEREST}

The authors declare no conflict of interest.

\section{ABBREVIATIONS}

HCV: Hepatitis C Virus; GT: Genotype; RNA: Ribonucleic acid; HCC: Hepato-Cellular Carcinoma; IV: 
Intravenous; NS: Non-structural protein; PCR: Polymerase chain reaction.

\section{REFERENCES}

1. Schietroma I, Scheri GC, Pinacchio C, Statzu M, Petruzziello A, Vullo V. Hepatitis C Virus and Hepatocellular Carcinoma: Pathogenetic Mechanisms and Impact of Direct-Acting Antivirals. Open Virol J. 2018;12:16-25.

2. Tolmane I, Rozentale B, Arutjunana S, Jeruma A, Kuse V, Simanis R. Original Versus Generic Direct Acting Antivirals in Treatment of Chronic Hepatitis C Patients: Real Life Data From Latvia. Open Infect Dis J. 2018;10(1):63-70.

3. Wong $\mathrm{N}$, Lee $\mathrm{C}, \mathrm{Ng} \mathrm{S}$, Wong H, Chan D, Lee S. Prevalence of hepatitis C infection and its associated factors in healthy adults without an identifiable route of transmission. J Viral Hepat. 2018;25(2):161-70.

4. GBD 2013. Mortality and Causes of Death Collaborators. Global, regional and national age-sex specific all-cause and cause-specific mortality for 240 cases of death, 1990-2013: a systematic analysis for the Global Burden of Disease study 2013. Lancet. 2015;385(9963):117171.

5. Borgia SM, Hedskog C, Parhy B, Hyland RH, Stamm LM, Brainard DM, et al. Identification of a Novel Hepatitis $C$ Virus Genotype from Punjab, IndiaExpanding Classification of Hepatitis C Virus into 8 Genotypes. J Infect Dis. 2018;40:1-8.

6. Satsangi S, Chawla YK. Viral hepatitis: Indian scenario. Med J Armed Forces India. 2016;72(3):204-10.
7. Mahajan R, Midha V, Goyal O, Mehta V, Narang V, Kaur K, et al. Clinical profile of hepatitis $C$ virus infection in a developing country: India. JGH Open. 2018;33(4):926-33.

8. Gower E, Estes C, Blach S, Razavi-Shearer K, Razavi H. Global epidemiology and genotype distribution of the hepatitis $C$ virus infection. J Hepatol. 2014;61(1):S45-S57.

9. Yao N, Hesson T, Cable M, Hong Z, Kwong A, Le H, et al. Structure of the hepatitis C virus RNA helicase domain. Nat Struct Mol Biol. 1997;4(6):463.

10. Hnatyszyn $\mathrm{HJ}$. Chronic hepatitis $\mathrm{C}$ and genotyping: the clinical significance of determining HCV genotypes. Antiviral Therapy. 2005;10(1):1-11.

11. Smith DB, Bukh J, Kuiken C, Muerhoff AS, Rice CM, Stapleton JT, et al. Expanded classification of hepatitis $C$ virus into 7 genotypes and 67 subtypes: Updated criteria and genotype assignment web resource. Hepatol. 2014;59(1):318-27.

12. Murphy DG, Sablon E, Chamberland J, Fournier E, Dandavino R, Tremblay CL. Hepatitis C virus genotype 7, a new genotype originating from central Africa. J Clin Micro. 2015;53(3):967-72.

13. Simmonds P, Holmes E, Cha -A, Chan -W, McOmish F, Irvine B, et al. Classification of hepatitis $C$ virus into six major genotypes and a series of subtypes by phylogenetic analysis of the NS-5 region. Journal Gen Virol. 1993;74(11):2391-9.

14. Prakash S, Shukla S, Ramakrishna V, Jain A. Distribution of hepatitis C genotypes in Uttar Pradesh, India; rare genotype 4 detected. J Me. Virol. 2018;90(12):1875881.

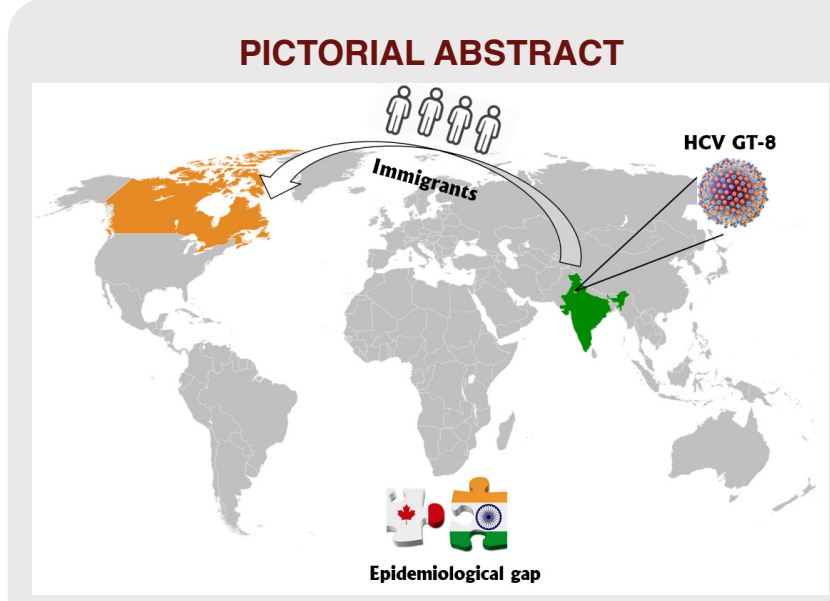

\section{About Authors}

- Hepatitis C Virus is a single-stranded RNA virus that belongs to the genus Hepacivirus of family Flaviviridae which is highly diverse and pervasive disease around the globe, with a prevalence ranging from 1.5 to $2.3 \%$.

- HCV was categorized into seven genotypes with 67 subtypes until the discovery of genotype 8 that added 17 subtypes to the family of HCV, which make up the total to 8 genotypes with 84 subtypes.

- Getting familiarized and making aware of the HCV genotypes and subtypes is necessarily essential in establishing the optimal treatment regimen.

- There exists an epidemiological gap, as all the four patients reside in Canada; however, they were originally from India.

- Thus, further robust research is needed in the resource-limited countries like India, where the $\mathrm{HCV}$ is considered as an epidemic, to discover additional patients with GT 8.

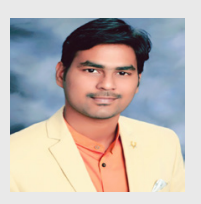

Dr. Sai Krishna Gudi, is a Ph.D. research scholar at the College of Pharmacy, University of Manitoba, Canada. Of now, he has authored around 30 papers that were published in both national and international journals. So far, he has attended various seminars, conferences and workshops, and presented numerous poster and oral presentations in the field of Pharmacy around the world. Besides, he is a member of numerous national and international societies. Throughout his journey in the profession of Pharmacy, he has received various scholarships and awards for his academic and research excellence. His research interest includes knowledge translation through Evidence-Based Practice, Optimizing Rational Drug-use, Pharmacoepidemiology, Pharmacy Education, Pharmacist Interventions, Patient-oriented Outcomes, and various aspects of Pharmacy Practice and Clinical Pharmacy. 
Dr. Manik Chhabra, is alumni of Indo-Soviet Friendship College of Pharmacy, Moga, Punjab. He is also a founder president of the International Society of Pharmacoeconomics and Outcome Research, Student Chapter- ISFCP. He has 25 publications published in national and international journals to his credit. He has expertise in conducting primary studies and meta-analysis. He is interested in Pharmacoepidemiology and Outcome Research. Currently, he is working as an ICMR Research Assistant at National Institute of Pharmaceutical Education and Research, SAS Nagar, Mohali.

Mr. Muhammed Rashid, is a B.Pharm and M.Pharm alumni of JSS College of Pharmacy, Mysuru, Karnataka, and he also obtained a Gold Medal for his academic merit in M.Pharm at the JSS University. He is currently serving as an Assistant Professor and ISPOR Faculty Advisor Student Chapter, Adichunchanagiri University, BG Nagara, Karnataka. Muhammed Rashid has expertise in conducting Systematic Literature Reviews and Meta-analysis. He has been to 9 conferences as a guest speaker and has published 15 papers in National and International Journals.

Cite this article: Gudi SK, Chhabra M, Rashid M. Genotype-8: A Modern Family Member of Hepatitis C Virus. Indian $\mathrm{J}$ of Pharmaceutical Education and Research. 2019;53(4s):s518-s521. 